\title{
Motivational Profile and the Inclination of the Career of Student of Information Technology
}

\author{
Evelyn Souto Martins ${ }^{1}$, Fernando Kuschnaroff Contreras ${ }^{2}$ \\ ${ }^{1}$ Brazilian School of Public and Business Administration of Getulio Vargas Foundation (EBAPE/FGV), \\ Rio de Janeiro, Brazil \\ ${ }^{2}$ Brazilian School of Public and Business Administration of Getulio Vargas Foundation (EBAPE/FGV), \\ Curitiba, Brazil \\ Email: evelynmueller@terra.com.br, contrerasfernandok@gmail.com
}

Received 8 May 2014; revised 10 June 2014; accepted 16 July 2014

Copyright (C) 2014 by authors and Scientific Research Publishing Inc.

This work is licensed under the Creative Commons Attribution International License (CC BY).

http://creativecommons.org/licenses/by/4.0/

(c) $\underset{\mathrm{EY}}{\mathrm{EY}}$ Open Access

\section{Abstract}

The area of information technology (IT) has undergone constant changes that, consequently, impact directly on professional and in companies that work with this sector. The aim of this study was to identify the motivational profile and the slope on the professional career of the student. This is a field which is applied in questionnaires closed with students. The sample was composed 94 students of two universities of computer in Brazil. Two instruments used were the inventory of Schwartz values (IVS) that offer some perspectives of appreciation of employee matching your goals and interests, and the other instruments were the questionnaire by Edgar Schein on professional inclination, which allows you to identify the relationship and prospects of those with work and their lives. The results reveal that students and IT professionals surveyed here are self-determined individuals who value the lifestyle, benevolent and hedonists, seeking the welfare and satisfaction in work and love challenges. Then we conclude that professionals and IT students are or will be, mostly professionals looking for constant challenges and personal and professional satisfaction, adapting the work as best as possible to your lifestyle.

\section{Keywords}

Professional Preference, Information Technology (IT), Motivational Profile

\section{Introduction}

The recent years have been marked by great technological development in multiple threads. The information

How to cite this paper: Martins, E.S. and Contreras, F.K. (2014) Motivational Profile and the Inclination of the Career of Student of Information Technology. American Journal of Industrial and Business Management, 4, 385-393. 
technology sector is one of whom has experienced the fastest transformations. The connection of computers with telecommunications and information resources originated the technological revolution in which we live, promoting changes in people's way of life. This new lifestyle is being marked by the computer age that brought with it the need for the emergence of new professions to meet the needs of knowledge and development of this area.

Professionals in the area of information technology (IT) have been increasing their importance to business performance. Advances in computing and communications technologies are affecting the processes of generation, distribution and storage of knowledge in organizations.

Information technology professionals are the current responsible for the evolution of the technological world. Concurrently with this evolution of technology and new professionals, a new kind of relationship seems to be occurring between the professionals of this area and businesses; being, then, the profile of this little-known relationship, making necessary studies that clarify this new professional profile. Demands are made of professionals with regard to differentiated knowledge and ability to act in the current business environment.

Career is defined as being the set of self-perceptions for the talents and skills, motives and needs, attitudes and values that people have with respect to work developing or seeking to develop [1]. Career also refers to the forces that drive each person to a certain behavior, i.e. are the variables intrinsic to the job and that influence the degree of satisfaction of people at work because inclination of career is based on interaction between skills, motives and values in total self-concept [2].

In relation to the inclination of career in the professional life of a person, it can be used to guide, mark out, stabilize and integrate the career of a person [3]. The motivational process can help the institution with respect to productivity to the same extent that the group based on different ways of motivation will achieve the best way to achieve the so-called efficiency. How is the motivation of people? What can be done to motivate them? What are their values and what do they want from their professions? They are crucial for the development of the company and the people [4].

The complexity of factors that involve human behavior and also the need to generate responses to new forms of life led to the investigation of different areas of knowledge, in order to contribute to the maintenance of the individual motivated in the company.

The organizational values, originated from human values, have been highlighted as a management tool for performance, due to the large subjectivity that permeates the theme, much appreciated by social psychologists social scientists and politicians, but very little for business managers [5]-[8].

Values are guiding principles for the life of the organization. Fail to consider the importance of this theme in the analysis of the company's performance would be a ravenous abstraction [9].

The values are able to influence the actions, choices and human behavior, interfering in the way in which the individual judges himself and others. They may be perceived, both as a product, as a point of reference for the process of reflection and evaluation of desires [10]. The values in this sense, affect people's reactions about his work, and allies to motivations and to stimulate talent career decisions, the ambitions of professional life and the satisfaction of priority needs of the individual [11].

The self-knowledge, the centrality of the structure of personality, triggers the recognition of personal demands, which include career preferences. Starting from this premise, you can infer the existence of a close relationship between the values and the slopes of career, since those are personal priorities and needs that guide attitudes, choices and behavior [12].

Understanding the influence of human values in determining the professional inclinations allows knowing how the professionals receive influence predispositions of centrality of the cognitive system, that is, of the values, which are designed as criteria capable of influencing the actions, choices and human behavior, interfering in the way in which the individual judges himself and others. In this sense, the human values affect people's actions on your work; allies to motivations and talents, stimulate career decisions [7]. The studies of the Masschutsetts Institute of Technology identified eight categories of career leanings, which are stimulated by appetites, feelings and needs which are established from the self-concept. Starting from this premise, you can infer the existence of a close relationship between human values and professional inclination. The study emphasizes the values and the slopes in the career of future professional, whose growth is increasing at universities and in companies.

\section{The Motivational Structure of Values}

It is very important to the study of values within the context of the Administration and management of people, 
because within these there are numerous factors related directly to values. The values that determine the behavior and performance of employees; influence in the vision that employees have of the company, colleagues and their managers [13]. Knowing the values of its employees, the relationship of the company with the same would be facilitated, which may generate strategies that could lead to competitive advantages.

The meaning that people seeks in his work is determined by your needs, by their values, and the values of others [13]. The values determine the options of people as well as the emotional responses to these options. The demand of employee in the company is directly related to how he is treated and respected; your demand depends also if it finds the Organization opportunities that meet your needs and help you achieve your goals and expectations, through the activity of the work [8]. When the individual joins a company has as basic interest increase profit, but rather to satisfy your personal needs of various orders. If the employee is not at work the means to satisfy your expectations, you won't feel a relationship of Exchange and exploration.

The motivational structure of a person is based on the set of targets which activate your behavior and the relationship between these motivations. Motivational profile refers to the importance that the motivations that drive his life have for each person [8].

The values represent the cultural requirements, in addition to the individual needs. The goals and intentions regarding the three basic elements of motivation: intensity, direction and persistence [5].

The motivational structure serves as a reference for drafting the motivational profile, which consists of the relative importance that each one of the motivations for each person. Through this structure you can determine what are the motivations and most important goals for the employee.

The values can be set as the goals fixed for the individual himself, concerning States of existence (terminal values) or desirable behavior models (instrumental values). Its root is motivational intent, because express interests and individual, collective or mixed desires [13]. The values show a hierarchy of the greater or lesser importance and a function that determines the daily routine of the individual establishing thus his way of acting, thinking and feeling.

Depending on the type of motivation or goal that the value expressed will make the difference between a value and another. The motivational types of values were deducted from the basic requirements of human beings, namely: 1) biological needs of the organism; 2) social needs concerning the regulation of interpersonal interactions; 3) socio-institutional needs regarding the survival and welfare of groups [14].

The motivational types already verified empirically are presented below.

Hedonism: The gratification of physical needs is transformed into socially recognized values. The goal of this group of motivational values is the pleasure and sensual gratification for himself [15] [16]. As an example of values has the pleasure and self-indulgence. It's an individual interest [14]. A hedonistic person is a person also stimulated in search of changes that will always be in front, to always be better than colleagues; be better than the other, not to contribute, but to maintain a position, that is what motivates.

Self-realization: Your goal is personal success obtained by a demonstration of competence that usually leads to social recognition [15] [16]. Example of values is being successful, capable, influential and ambitious. The self-realization is considered an individual interest [14]. The motivational type realization (Self-realization) is directly linked to the quest for power, in that the greater the power, the greater the achievement.

Social power: The goal of this type of value is the demand for status, prestige and social control over people and resources [15] [16]. Example of this type is the concern with the power, wealth and authority and is characterized by an individual interest [14].

Self-determination: The values of self-determination seeking independence of thought, action, option, curiosity, creativity, freedom to choose their own targets [16]. Has an example of values freedom, creativity, curiosity and independence. It is characterized by an individual interest [14].

Compliance: Your motivational goal is the control of impulses and the own behavior in accordance with social expectations [15] [16]. Example values are obedience, politeness, self-discipline. Compliance is considered as a collective interest [14].

Benevolence: The values that make up the motivational type benevolence are: availability, honesty, loyalty, responsibility, friendship, maturity and work. The motivational goal is the interest and concern for the well-being of people intimate [15] [16], is helpful, loyal, forgiving, and worries about the collective interest [14].

Security: The goal of the values of this type is the personal integrity and identification of people and groups, as well as the stability of society and of himself [15] [16], with interest in the social order, family safety, clean- 
ing and revealing a joint interest [14].

Tradition: The goal of the figures relating to the motivational tradition is the respect and acceptance of the ideals and customs of their society [15] [16]. Respect to tradition, moderation and devotion and collective interest are its characteristics [14].

Stimulation: Need for excitement, novelty and change in order to be able to maintain a satisfactory level of operation [15] [16]. Life varied, exciting life and individual interest [14].

Philanthropy: The goal of this group of motivational values is the quest for the well-being of all. Schwartz calls this motivational type "universalism". [16] are your feature: equality, social justice, wisdom, respect for nature, a world at peace, equality, inner harmony and dream; it is a joint interest [14].

The motivational types of values relate to each other dynamically. The relationship has been verified through the method of analysis of smaller space that is a multidimensional analysis technique designed to determine the similarity of structure data. Through her values are represented as points in multidimensional space, in such a way that the distances between them express the empirical relationships between values, determined from the correlations among their degrees of importance, according to the responses of subjects [14]. The values in the service of individual interests are opposite to those that serve collective interests [6] [16]. Thus, postulate two basic types of relationships between them: of compatibility and conflict. On the motivational structure, the five types of values that express individual interests (self-determination, stimulation, hedonism, achievement and social power) occupy a contiguous area that is opposite to that reserved for three sets of values that express primarily collective interests (benevolence, tradition and conformity).

Empirical studies carried out by means of multiple regressions have shown consistent ratio of motivational dynamics with the prediction of the behavior at work and in life in General [14]. Axiological priorities of the individual expressing, in addition to their motivations, their conceptions of what is good for himself, to society and to the organization where he works.

Motivational profile is elaborated based on the motivational structure, consisting of the relative importance that each one of the motivations for each person. The profile therefore implies a hierarchy of importance among the various motivations of the worker. Through this, one can distinguish what are the motivations and goals more important to him, as well as those occupying a second or third plane. In addition, the detailed analysis of personal motivation may be supplemented through integration of the ten motivations in two-dimensional structure, which allows a more global vision, and maybe more consistent, the organization and direction of employee motivational forces [8].

The ten employee motivators feature a two-dimensional structure. The four poles that make up these two dimensions represent the person's motivations and define four motivational sets, which are the fundamental openness to change, conservation, self transcendence and self-promotion [8].

Seeks to change expresses expectations and goals that can be attained through the autonomy given to the worker to perform his work, thus offering you opportunities to create and innovate.

At the opposite side, lie the interests and expectations of the person in relation to conservation. The occupational safety and in the job, salary, clear and precise objectives and standards, quality circles, appropriate physical space, regular schedule and favorable conditions for the execution of the work, constitute appropriate organizational actions to meet the expectations and targets related to this motivational side.

The motivation of self transcendence focuses on collective results and well-being of everyone in the organization. The goals for this motivation can be attained through a pleasant social environment, without conflicts, with opportunities to interact with colleagues and customers. Finally, the self-promotion, which expresses mainly targets related to personal results, requires organizational actions such as those related to financial incentives, benefits and opportunities to promote recognition of merit.

To enable the adequacy between the motivational profile of the worker and concrete actions of motivation is necessary to be able to determine the motivational profile of employees to be able to identify from the predominant motivations and power, from these data, draw up strategies of motivation to work. One of the best and most suitable instruments for this evaluation is the inventory of Schwartz values (IVS).

While researching the purpose culture Values hierarchy and Brazilians, used as a method to scale prepared by Schwartz (1992) for a purpose culture research. It consists of 57 values [6] [16]. Were also introduced over four values, two terminals (and vanity) and two instrumentals (smart and dreamer), postulated as being peculiar to the Brazilian culture.

Identify the motivations of professionals regarding personal professional leanings was another objective of 
this work. Professional inclination as being the set of self perception for the talents and skills, motives and needs, attitudes and values that people have with respect to work developing or seeking to develop. The instrument used to identify the student and Professional Inclination of the it Professional is based on the book by Schein [1].

Are described the characteristics of each type of reference to see how people with different inclinations differ from each other [11].

Technical-professional fitness: What motivates this kind of person is exercising their skills and the satisfaction of knowing that they're experts. The type of work for individuals with these characteristics is the challenge. In addition to continuing education, this group values the formal recognition.

Fitness in general: Fundamental values and goals for this group of people are summed up in the steps to achieve the company's hierarchical higher levels of responsibility, have the opportunity to lead, contribute to the success of your organization and receive high yields.

Autonomy: Independence people with a penchant for autonomy and independence do not support rules, methods, work hours and other rules common to virtually any type of organization. Regardless of your business, these people like to do things your way, at your pace and according to their own standards.

Security stability: People with inclination to make security a predominant factor throughout their careers, to guide and limit their main professional decisions. These people typically seek employment in organizations that provide security and stability.

Entrepreneurial creativity: Some people have a great need to create new businesses, developing new products or services, organizing new companies or managing them according to your specifications and they succeed.

Willingness to serve, dedication to a cause: Individuals with features serving give values to help humanity, the nation, and to dedicate themselves to a cause. People in this group want a job that will allow them to influence the organizations that employ them or social policy, in the direction of its values.

Pure challenge: Some people are based on the perception that can conquer anything or anyone. For them, success is impossible or overcome obstacles overcome strong opponents. Living in the world where everything is to compete and win.

Lifestyle: This type of person prefers flexibility above all. People-oriented lifestyle seeks one more organizational attitude than a specific program, an attitude that reflects respect for personal and family interests. Who has this slope likes to reconcile personal, family and professional needs.

Almost everyone can identify their true inclinations if submit themselves these situations of choice [11]. The reference points do not change, can sometimes, lack of experience, not being well formed. People can try to adapt to the situation, but their leanings will not change; as soon as an opportunity arises, will combine better occupation and professional inclination.

Is of fundamental importance to combine the individual needs with organizational, so the professional must have their professional inclination perception in order to better plan their careers and be able to make better choices. The complicated in this process are individual differences as well as the differences between the companies. Organizations should better analyze the specific features of the different functions to be exercised in a particular career and clarify them to individuals who are interested in pursuing such a career.

\section{Methodology}

This work made use of the technique of questionnaires characterized then as a field research, which is one that aims at obtaining and empirical data. In the development of this survey questionnaires were used.

The sample universe refers to professionals and students. The sample was composed by students from two universities computing in Rio Grande do Sul-Brasil. It is a probabilistic sample by conglomerates.

The two questionnaires used are characterized by being structured questionnaires, i.e. consist of closed questions. There was, before the questions, a letter of introduction, explanation and thankfulness. Some of the instruments was the questionnaire of Schein (1996), which sought to identify the students 'motivations of TI concerning personal professional inclinations. The other is the Inventory of values of Schwartz, who checked the motivational profile of students [11].

Professional Inclination scales Schein consists of a rating scale. The classification of the sum stems from an adaptation of Likert scale which causes reactions in respondents, which, in turn, to manifest through points with numeric values; in the end, allows the total sum corresponding to each dimension-in this case, the categories of 
professional inclination or also known as career anchors.

The questionnaire of Schein consists of forty questions. The responder must score if the question is ever applied to him or always be applied on a scale. Altogether were affirmative 40 that the respondent should assign classification of 1 to 6 , but due to the pilot study only the first 24 statements were used and in order to facilitate, to the respondents that used two different instruments, the scale was modified to be the same as the inventory of Schwartz of 0 to 5 . The scale of assessment used for the questionnaire of Schein in this work was:

The other instrument used was the Schwartz Value Survey. He intended to raise the motivational profile of employees. In that instrument contained 57 values; the Brazilian version was adapted four characteristic values of Brazilian culture. The importance of the values was assessed using a scale of 0 to 6 . The higher the number the more important was the value to the person. In addition, we used the numbers 1 and 7 ; the first to assess any opposing values to those of the person and the second to assess a value of supreme importance for the evaluated. In this research, the Likert scale which is recommended for measures of attitudes and perceptions and was used in the original instruments of Schein and Schwartz that have been preserved with only changes in the numbering.

The rating scale used in the inventory values of Schwartz used was:

(0) Opposite to my values; (1) unimportant; (2) unimportant; (3) Important; (4) very important; (5) Of supreme importance.

The responses were tabulated and sorted according to the average scores obtained by respondents in the various motivational types, and so determine the motivations or goals that are a priority for this sample. After the questionnaires were answered by the students, the results were tabulated table in an Excel spreadsheet. Content analysis of responses obtained through the application of questionnaires, seeking to relate the motivational profile and the inclination of students 'career, with its conclusions and recommendations. The data from the two questionnaires were analyzed using a quantitative analysis, from the application of statistical functions as mean and standard deviation. It is a descriptive research, because it aims to describe the motivational profile and the inclination of the student's career.

\section{Statistical Results and Analysis of the Research Data}

Independent of the working environment is likely to find people who, although exercising the same function and exposed to similar conditions, behave differently. This is because people have stories of different lives, their own experiences, experiences, values, needs and goals [17]. However, motivational theories show that, despite the characteristics and personal differences, many needs are a part of the human universe. Inventory of values was filled by students of computing. The values that make up the inventory values are common to different cultures. For each value is presented an explanation about his concept, aiming to clarify, in order to facilitate the choice that was made with good safety margin. The statistical results of the data collected from the inventory of values with 61 items referred to the question posed to individuals here searched: "what values are important to me, as guiding principles in my life, and what values are less important?”

By checking the results, it clearly shows that students pursue individual interests and the things that are in adjacent areas: self-determination, hedonism and self-actualization.

The self-actualization has as goal the personal success obtained by a demonstration of competence that usually leads to social recognition [15] [16]. Example of this value is to be successful, capable, influential and ambitious. Hedonism is characterized by physical needs bonus which is transformed into a socially recognized values, and has as its main focus the pursuit of pleasure and avoiding pain and suffering; Search the satisfaction and well-being at work. The goal of this group of motivational values is the pleasure and sensual gratification for himself [15] [16]. The pleasure and self-indulgence are examples of these values (Table 1).

The values in the service of individual interests are opposite to those that serve the collective interests [6] [16]. Thus, postulate two basic types of relationship among them: compatibility and conflict. On the motivational structure, the five types of values that express individual interests (self-determination, stimulation, hedonism, achievement and social power) occupy a contiguous area that is opposite to that reserved for three sets of values that express primarily collective interests (benevolence, tradition and conformity).

Individual interests of students characterized by giving greater importance to the values of self-determination, 
Table 1. Means and standard deviations motivational type of students.

\begin{tabular}{ccc}
\hline Motivational Type & Students & Detour \\
\hline Self-determination & $1^{\circ} 3.87$ & 0.29 \\
Hedonism & $2^{\circ} 3.76$ & 0.14 \\
Realization & $3^{\circ} 3.65$ & 0.57 \\
Benevolence & 3.64 & 0.68 \\
Compliance & 3.54 & 0.29 \\
Safety & 3.50 & 0.64 \\
Universalism & 3.34 & 0.52 \\
Tradition & 3.04 & 0.83 \\
Stimulation & 3.02 & 0.25 \\
Power & 2.71 & 0.50 \\
\hline
\end{tabular}

Source: Drawn by the author based on research.

hedonism and self-actualizing describing them with a profile of curiosity, creativity, freedom to choose their own targets, independence of thought/action and cultivation of self-respect.

The motivational type hedonism is characterized by the importance to pleasure and to enjoy life. A hedonistic person is a person also stimulated in search of changes that will always be in front, being always better (better than the others, not to contribute, but to maintain a position, here's what motivates) colleagues. This behavior can be valued through enjoyable activities at work. The motivational type realization (Self-realization) is directly linked to the quest for power, in that the greater the power, the greater the achievement. For the value selfactualization, which serves the individual interests, were grouped together values such as: success, ability, ambition, influence, intelligence and wit [18]. The goal of this motivational type is "[...] personal success obtained through a demonstration of competence that usually leads to social recognition.” [19].

The young computer students demonstrate an individualist profile where self-determination is in the pole seeks to change expressing expectations and goals that can be attained through the autonomy given to the worker to perform his work, thus offering you opportunities to create and innovate. While the hedonism and self-actualization are found in the pole of self-promotion, which expresses mainly targets related to personal results, requires organizational actions such as those related to financial incentives, benefits and opportunities to promote recognition of merit. Training and opportunities to use knowledge and skills are also a way to meet expectations and goals from this pole motivational.

It turns out that the most important career anchor of students is the style of life. This type of person prefers flexibility above all. People-oriented lifestyle seeks one more organizational attitude than a specific program, an attitude that reflects respect for personal and family interests. People who have this slope like to reconcile personal, family and professional needs (Table 2).

For the 94 students, second was the anchor of career Autonomy Independence. People with a penchant for autonomy and independence do not support rules, methods, work hours and other standards, common to virtually any type of organization. Regardless of your business, these people like to do things your way, at your pace and according to their own standards. These people prefer to follow more independent careers, according to their own standards; they are usually professionals.

The person with a tendency to prefer autonomy jobs, contracted projects that are well-defined goals and temporary to stay on their own mean to achieve them. She prefers payment by the merit of his performance, with payment at the end of your work. She always wants a new position that will give you more freedom than the previous one, namely, promotion means autonomy.

Thirdly and most important career anchor of students was the pure challenge since for students success is impossible or overcome obstacles overcome strong opponents. Living in the world where everything is competition and win.

Fourthly, it is becoming the anchor of functional technical-related career. What motivates this kind of person 
Table 2. Comparison of student professional inclinations.

\begin{tabular}{ccc}
\hline & \multicolumn{2}{c}{ Student } \\
\cline { 2 - 3 } & average & detour \\
\hline Lifestyle & 3.84 & 0.49 \\
Autonomy independence & 3.33 & 0.8 \\
Challenge & 3.27 & 0.39 \\
Functional technical & 3.23 & 0.48 \\
Administrative aptitude & 2.26 & 0.55 \\
Willingness to serve & 2.69 & 0.27 \\
Security & 2.87 & 0.32 \\
Creativity & 2.8 & 0.54 \\
\hline
\end{tabular}

Source: Drawn by the author based on research.

is exercising their skills and the satisfaction of knowing that they're experts. The individual with technical and functional incline is dedicated his whole life to specialization and doesn't value the position of General Manager, although accepts positions of technical managers. In regards to salary, he/she is more oriented towards internal equity and prefers to pay incentives. The type of work for individuals with these characteristics is the challenge. They need to exercise their capabilities. Otherwise, your self-esteem will not be satisfied. In addition to continuing education, this group values the formal recognition. For that person to remain at the company, and if it is of great importance for the same, you will need to create for her some kind of restructuring of career plan, coming to meet than above was reviewed.

It was noted, then, through the inventory of values of Schwartz and professional inclination questionnaire Schein students you here surveyed are individuals self determined. This means that they have priority for the independence and autonomy of thought, action and choice. Hedonists value the lifestyle, showing that this type of person likes to reconcile personal, family and professional needs. The main focus of hedonists is in pursuit of pleasure and avoiding pain and suffering with this, seek the well-being and job satisfaction. To complement, it is also important to mention that the individuals in this sample also love challenges.

\section{References}

[1] Schein, E. (1978) The Role of the Consultant: Content Expert or Process Facilitator? The Personnel and Guidance Journal, 56, 339-343.

[2] Tanner, N. (2004) Introduction to the General Theory of Management: Compact Edition. 3rd Edition, Rev. and Current. Rio de Janeiro: Campus.

[3] Kilimnik, Z.M., Castilho, I.V., Sant'anna and de Souza, A. (2006) Carreiras em Transformação e seus Paradoxais Reflexos nos indivíDuos: Metáforas de Carreira e de Competências. Comportamento Organizacional e Gestão, 12, 257-280.

[4] Oliveira, S.L.D. (2002) Sociology of Organizations: An Analysis of the Man and of the Companies in the Competitive Environment. Pioneer Thomson Learning, Sao Paulo.

[5] Rokeach, M. (1981) Beliefs, Attitude and Values: A Theory of Organization and Change. Interciencia, Rio de Janeiro.

[6] Schwartz, S.H. (1992) Univelsal in the Content and Structure of Values: Theoretical Advanced and Empirical Tests in 20 Coutries. In: Zanna, M. (Org.), Advanced in Social Psychology Experiment, Academic Press, New York, 1-65.

[7] Schein, E. (1993) Redesign of Positions and Functions. Nobel, São Paulo.

[8] Tamayo, Á. and Paschoal, T. (2003) The Relationship of Motivation to Work with the Goals of the Employee. Contemporary Administration Magazine, 7, 33-54.

[9] Tamayo, A., Mendes, A.M. and Paz, M.D.G.T.D. (2001) Inventário de Valores Organizacionais. Estudos de Psicologia, 5, 289-315.

[10] Schwartz, B. and Lacey, H. (1995) The Formation and Transformation of Values. Journal of the Faculty of Psychology of the PUC, 1, 91-123.

[11] Schein, E. (1996) Professional Identity: How to Adjust their Leanings to Their Work Options. Nobel, São Paulo.

[12] Stackman, R.W., Pinder, C.C. and Connor, P.E. (2004) Values Lost: Redirecting Research on Values in the Workplace. 
In: Ashkanasy, N.M., Wilderom, C.P.M. and Peterson, M.F., Eds., Handbook of Organizational Culture and Climate, SAGE, Santa Monica.

[13] Tamayo, Á. (2000) Axiológicas Priorities and Satisfaction at Work. Administration Magazine, 35, 37-47.

[14] Tamayo, A. and Mendes, A.M. (2001) PEACE, Maria das Graças Towers. Organizational Values Inventory. Studies of Psychology, Christmas, 5, 289-315.

[15] Tamayo, Á. (2002) Emotional Exhaustion at Work. Administration Magazine, 37, 26-37.

[16] Tamayo, A. (2007) Transcultural Values Hierarchy and Brazilians. Psychology: Theory and Research, 23, 7-15.

[17] Lévy-leboyer, C. (1994) The Crisis of the Motivations. Atlas, São Paulo.

[18] Tamayo, A. and Schwartz, S.H. (1993) Estrutura Motivacional dos Valores Humanos. Psicologia: Teoria e Pesquisa, 9, 329-348.

[19] Tamayo, Á. (1994) Hierarquia de Valores Transculturais e Brasileiros. Psicologia: Teoria e Pesquisa, 10, $269-285$. 
Scientific Research Publishing (SCIRP) is one of the largest Open Access journal publishers. It is currently publishing more than 200 open access, online, peer-reviewed journals covering a wide range of academic disciplines. SCIRP serves the worldwide academic communities and contributes to the progress and application of science with its publication.

Other selected journals from SCIRP are listed as below. Submit your manuscript to us via either submit@scirp.org or Online Submission Portal.
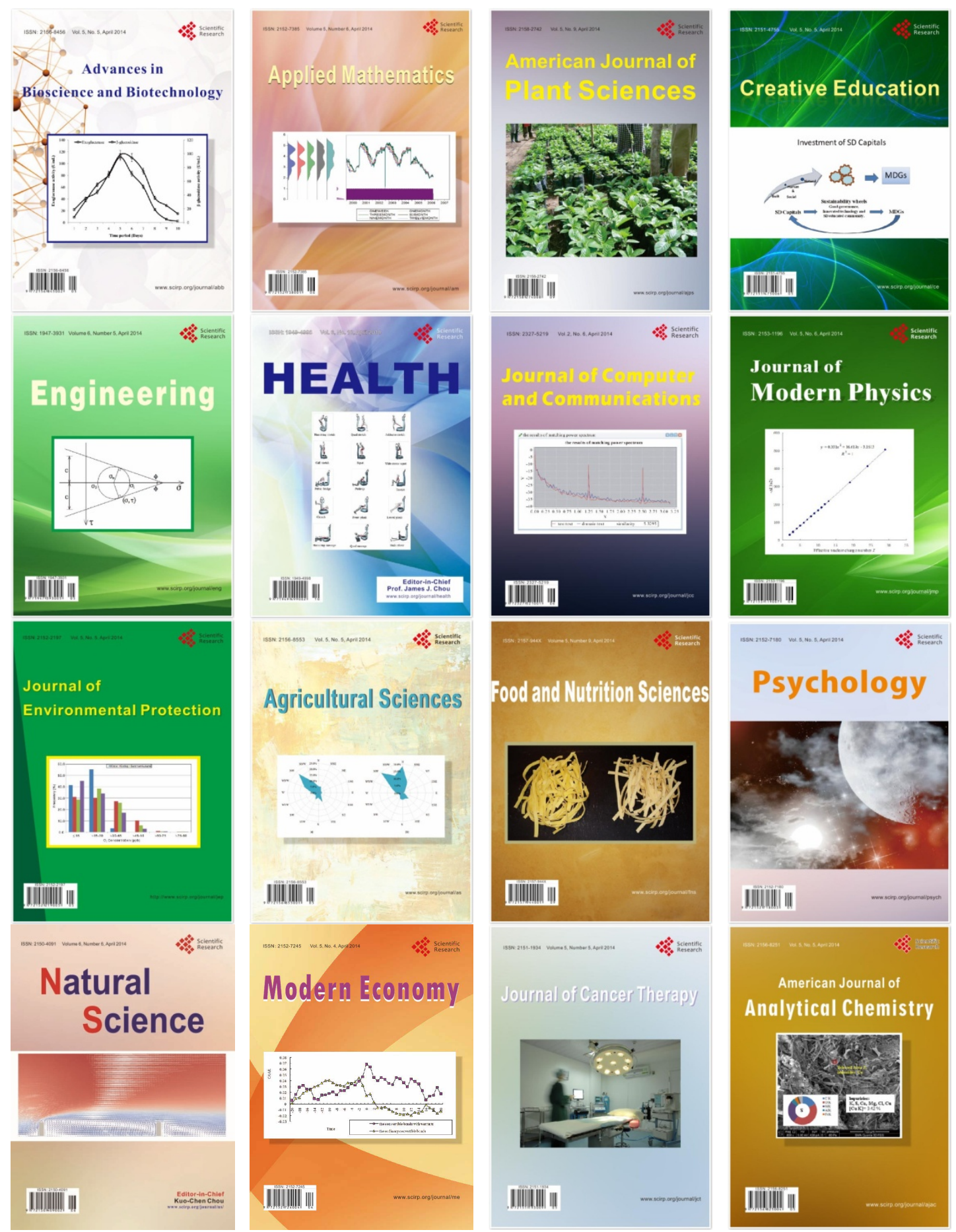